\title{
ESTADO Y SINDICATOS EN LOS AÑOS TREINTA. EL VÍNCULO ENTRE EL DEPARTAMENTO NACIONAL DEL TRABAJO Y LA UNIÓN OBRERA TEXTIL
}

\section{Diego Ceruso*}

Universidad de Buenos Aires / Consejo Nacional de Investigaciones Científicas y

Técnicas (CONICET)

$\bowtie$ diegoceruso@gmail.com
Recibido: 18 de agosto de 2020

Aceptado: 30 de octubre de 2020

DOI: $10.46553 /$ colec.32.1.2021.p159-187

Resumen: El trabajo revisa la dinámica del Estado y los sindicatos en los años treinta con el objetivo de aportar a un mejor conocimiento de la experiencia del vínculo entre las instituciones laborales y las organizaciones obreras de aquella época. En particular, se aborda la experiencia del Departamento Nacional del Trabajo en relación a uno de los sindicatos industriales de mayor crecimiento del periodo, la Unión Obrera Textil. Para ello también se enfoca el despliegue del Partido Socialista en el mundo gremial pues sus cuadros orientaron el sindicato textil. Eso se hará con un nutrido cuerpo documental que incluye fuentes estatales, gremiales y partidarias de diversa índole y procedencia.

Palabras clave: Departamento Nacional del Trabajo; Unión Obrera Textil; Partido Socialista; Década infame

Abstract: The work reviews the dynamics of the State and the unions in the thirties with the aim of contributing to a better knowledge of the experience of the bond between labor

\footnotetext{
* Doctor de la Universidad de Buenos Aires con mención en Historia. Investigador adjunto del Conicet con sede en el Instituto de Historia Argentina y Americana "Dr. Emilio Ravignani”.
} 
institutions and workers' organizations of that time. In particular, the experience of the National Labor Department in relation to one of the fastest growing industrial unions of the period, the Unión Obrera Textil, is addressed. For this, the deployment of the Socialist Party in the trade union world is also focused as its cadres guided the textile union. This will be done with a large documentary body that includes state, union and party sources of various kinds and backgrounds.

Keywords: National Labor Department; Unión Obrera Textil; Socialist Party; Infamous decade.

\section{Introducción}

La intención de nuestro trabajo recala en el análisis conjunto del Estado y los sindicatos en los años treinta a partir del estudio del vínculo entre el Departamento Nacional del Trabajo (DNT) y la Unión Obrera Textil (UOT) en la Capital Federal y sus alrededores con el objetivo que ello nos brinde elementos para pensar de modo más general la articulación entre agencias estatales y organizaciones sindicales en aquellos años. Entendemos que enfocar la dimensión organizativa de la clase trabajadora en correspondencia con la acción del Estado habilita una dimensión que enriquece el examen. Procuramos no observar este elemento como un camino homogéneo ni unilateral. Es decir, por ejemplo, el ejercicio estatal puede ser reconstruido tanto en la faz coercitiva como en la consensual, dos caras de la misma moneda, y ponderar momentos en los que una prima sobre otra (Gramsci 1981). Al posar nuestro interés en las relaciones entabladas por el DNT, sin desconocer el resto de los organismos nacionales y provinciales de negociación (Ministerio del Interior, Departamento Provincial del Trabajo, etc.), ciertamente la dimensión consensual obtiene preponderancia aunque referiremos de modo colateral a elementos de represión específicos y a la labor de las estructuras abocadas a ello como la Sección Especial de Represión del Comunismo, la Dirección de Inteligencia de la Policía de la Provincia de Buenos Aires o la Sección de Orden Social de la Policía de la Capital Federal, entre otras. Además, la estrategia estatal 
debe ser cotejada en sus modulaciones y variaciones pues pudo no ser uniforme y modificarse de acuerdo a múltiples factores como los sectores económicos o corrientes políticas intervinientes. Por caso, en determinadas áreas de la economía, la existencia de sindicatos conducidos por tendencias políticas más permeables a la negociación pudo alterar la acción meramente represiva del Estado.

Para ello nos serviremos primariamente de las diversas publicaciones oficiales del DNT, del órgano oficial del Partido Socialista, La Vanguardia, y del periódico del sindicato, El Obrero Textil. Asimismo, buscamos enriquecer el texto con el entrecruzamiento documental y reparamos colateral y puntualmente en fuentes empresariales, estatales de otra índole que las del DNT, pertenecientes a otras corrientes partidarias como el comunismo y de la Confederación General del Trabajo, principal central obrera de la época. Así, el objetivo es dar cuenta del modo más profundo posible de la dinámica particular de la experiencia en la que intervinieron el Estado, el partido político, el sindicato y la clase trabajadora.

\section{El Departamento Nacional del Trabajo, el Partido Socialista y el gremio textil}

En el proceso de construcción y posterior consolidación del Estado nacional, la definición de tareas y áreas de influencia cumplió un importante rol desde fines del siglo XIX. Para nuestro trabajo, en el entramado institucional estatal resulta ineludible la fecha de 1907 con la creación del DNT en el marco del Ministerio del Interior. ${ }^{1}$ Fue en 1912 cuando se sancionó la ley 8.999 que modificó sus tareas otorgándole una perspectiva de resguardo de las leyes laborales. Además, en dicha legislación se preveía como novedad la creación de 'consejos del trabajo', también conocidos como 'de patronos y obreros', con la intención de habilitar un espacio de negociación conjunta. A partir de allí, el DNT buscó implementar sus dotes

\footnotetext{
${ }^{1}$ Inicialmente, el DNT operó con un número escaso de empleados provenientes de diversos espacios políticos, intelectuales y societales y sus funciones priorizaban la recopilación de datos, pero no la regulación de la escasa legislación vigente. Soprano 2007.
} 
de arbitraje estatal con diferentes énfasis dependiendo de las administraciones, coyunturas, sectores productivos, recursos, entre los múltiples factores. Aún con los intentos de federalizar su influencia, para los años que nos ocupan, el DNT desarrollaba su práctica en términos concretos y geográficos en la Capital Federal sin poder extender todavía su injerencia al resto del país aunque ciertamente se mostró activo en establecer relaciones con las estructuras laborales provinciales. ${ }^{2}$

Una vez consumado el golpe de Estado de 1930, como se ha dicho, entre las filas marciales existían dos referentes nítidos: José F. Uriburu y Agustín P. Justo. Aunque de modo poco sustancioso y más bien difuso, Uriburu representaba el sector nacionalista con un proyecto de corte corporativista y refundacional sobre los caducos cimientos democráticos. ${ }^{3}$ El día 6 de septiembre amaneció con la noticia que el vicepresidente Enrique Martínez, en quien Hipólito Yrigoyen había delegado el mando en los días previos, había declarado el estado de sitio en la Capital Federal. Pero el putsch ya estaba en marcha. Para finalizar la puesta en escena, la Corte Suprema de Justicia de la Nación decidió en su acordada reconocer al nuevo gobierno. ${ }^{4}$

De conjunto, existían sectores que conformaban la vertiente que encabezó la represión más frontal contra el movimiento obrero y sus instituciones aunque ciertamente no eran los únicos componentes. La otra tendencia muy marcada dentro del régimen abrevaba en el corporativismo y ancló sus políticas en el DNT para impulsar desde allí los cambios que se propugnaban (entre otros: Soprano 2000; Bertolo 2011). El más visible de los funcionarios enrolados en estas ideas fue el presidente del DNT Eduardo Maglione quien intentó desplegar las políticas de subordinación de los sindicatos al Estado junto a cierto cumplimiento de leyes laborales existentes y reorganización del organismo a su cargo (Rubinzal 2013, 223229).

\footnotetext{
${ }^{2}$ Una mirada panorámica del DNT puede consultarse entre otros en: Soprano (2000); Lobato y Suriano (2013).

3 Por cuestiones de espacio y de objetivos no damos cuenta del debate sobre las motivaciones del golpe de Estado y el clima previo. Parte de las investigaciones que pueden consultarse para abordarlos son: Potash (1981, 21 y ss); Rock (2010, 264-265); Rouquié (1985, 210-219); Devoto (2002).

4 Acordada sobre reconocimiento del Gobierno Provincial de la Nación, Corte Suprema de Justicia de la Nación, 10/9/1930.
} 
Por su parte, el consenso historiográfico ha destacado el impulso recibido por la industria argentina tras los efectos más inmediatos de la crisis económica mundial a fines de 1929. La baja en los precios de los productos agropecuarios, el aumento de los aranceles a las importaciones, la instalación del sistema de control de cambios y la ruptura de los lazos comerciales a nivel mundial, entre otros motivos, potenciaron al sector industrial luego de unos años. Este crecimiento estuvo liderado por un conjunto de actividades productoras de bienes de consumo final que incorporaron un bajo nivel de tecnología en sus procesos productivos (Dorfman 1942; Schvarzer 1996). La recuperación económica se consolidó hacia mediados de la década y la industria textil se posicionó entre los sectores de mayor crecimiento (Korol y Belini 2012). Los estudios también verificaron que el área de mayor crecimiento del sector fue el conglomerado compuesto por la Capital Federal y los partidos bonaerenses colindantes. La fuerza de trabajo estaba integrada, mayoritariamente, por obreras y obreros de escasa calificación y compuesta principalmente por mujeres, muchas de ellas menores de edad (Horowitz 2004, 83-84). Como observaremos más adelante, este rasgo estructurante y tensionante de las relaciones sociales incidió en la dinámica estatal, sindical y de la clase trabajadora ofreciendo elementos para pensar la opresión específica de las mujeres (Vogel [1983] 2013).

Ese crecimiento del sector textil y el aumento numérico de la clase trabajadora se forjó en paralelo a la incidencia de las expresiones políticas de la izquierda argentina en la organización gremial. Aunque anarquistas y sindicalistas habían obtenido presencia en el sector, fueron los socialistas en primera instancia y luego los comunistas quienes lograron una presencia más sólida y estable que el resto de las corrientes políticas hacia los años veinte. Desde fines de 1929, los comunistas habían logrado desplazar de la conducción de la Federación Obrera de la Industria Textil (FOIT) a una alianza compuesta por 'penelonistas', anarquistas y socialistas. $^{5}$ En

${ }^{5}$ El Partido Comunista tuvo una crisis que se desenvolvió a partir de 1927 y ofreció como actor central a José Fernando Penelón, la figura más importante dentro del partido en los años veinte. La estructura surgida de esta escisión se denominó Partido Comunista de la Región Argentina, para la elección presidencial de 1928 adquirió el nombre de Partido Comunista de la República Argentina para finalmente adoptar, luego de 1930, el de Concentración Obrera (Ceruso 2014). 
consecuencia, a partir de allí existió la FOIT comunista enrolada en el Comité de Unidad Sindical Clasista (CUSC). ${ }^{6}$ Por otro lado, existía la Federación Obrera Textil (FOT) con gran presencia de socialistas, e injerencia más limitada de sindicalistas, y enrolada en las filas de la Confederación General del Trabajo (CGT), a partir de 1930. Para enero de 1934, los socialistas cambiaron el nombre de la entidad y finalmente adoptaron el de Unión Obrera Textil (UOT) con sede en la calle Alvarado 1963 del barrio porteño de Barracas. Los datos del sector promediando la década muestran un aumento en la cantidad de obreros ocupados y en el número de establecimientos fabriles. En 1935, la cantidad de trabajadores textiles sumaban 52.576 de los cuales 36.650 se desempeñaban en la Capital Federal. Estas cifras prácticamente se duplicaron para 1943. ${ }^{7}$ La instalación de grandes plantas adquirió relevancia hacia mediados de la década aunque no puede menospreciarse la existencia de medianas y pequeñas industrias. Las principales empresas textiles de la Capital Federal y alrededores, por su producción y por la cantidad de obreros ocupados, eran: Manufactura Algodonera Argentina, Fábrica Argentina de Alpargatas, Campomar y Soulas, Establecimientos Americanos Gratry, Ducilo, Piccaluga, Danubio y Salzmann, entre otras. Los socialistas tenían una maciza presencia en las fábricas instaladas en el sur de la Capital Federal entre las que se destacaban Salzmann y Piccaluga. Inicialmente, los socialistas plasmaron su superioridad designando a Basilio Dimópulo y luego a Juan Armendares como secretarios generales. Entre los cuadros del Partido Socialista (PS) en este gremio también se desempeñaban Demetrio Dimópulo, Lucio Bonilla, Cándido Gregorio, Juan Pardo, entre otros. Como luego explicaremos, los comunistas a partir de 1935 disolvieron su sindicato y se sumaron a la UOT. Dicha incorporación implicó la duplicación de la cantidad de afiliados.

\footnotetext{
${ }^{6}$ Tras la adopción de la línea estratégica de 'clase contra clase' los diversos sindicatos argentinos dirigidos por comunistas se agruparon en el denominado Comité de Unidad Sindical Clasista que pretendía funcionar más como una instancia articuladora, que vagamente llamaba a la unidad, que como una central obrera nacional (Camarero 2007). "Ha sido detenido Carlos Ravetto, secretario de Federación Obrera Textil Clasista ¡Luchemos por su inmediata libertad!”, volate de la Federación Obrera Textil adherida al Comité de Unidad Sindical Clasista, 1933.

${ }^{7}$ Dirección Nacional de Estadísticas y Censos, Cuarto censo general de la Nación, Buenos Aires, 1949, III, pp. 26-27.
} 
Entre los cuadros más importantes del Partido Comunista (PC) en los textiles estaban Próspero Malvestitti, Jorge Michellón, Dora Genkin, Ida Pecheny, Meyer Kot, José Freikes, por mencionar los más importantes. Para el año 1936, los afiliados rondaban un número cercano a 4.000, cifra exigua si se la compara con la de obreros ocupados en la industria, que se acercaba a los 70.000. Ante este panorama, la voluntad de la UOT en su conjunto era expandir su influencia y lograr una mayor inserción entre los obreros (Ceruso 2015).

Estudiar el movimiento obrero implica hacerlo en estrecha asociación con la izquierda, pues entendemos que la pretensión de aprehenderlos por separado desembocaría en un ejercicio trunco. Esto conlleva la tarea de encarar las características específicas y, al mismo tiempo, enfocar la relación entre ellos. Esta búsqueda de amalgamiento está basada en la convicción acerca de la dinámica conjunta que, de otro modo, quedaría mutilada en tanto presentaría caminos bifurcados (Comité editor, 2012). El objeto y la óptica, entonces, confluyen con el otro sujeto de este trabajo que es el Partido Socialista.

El repaso por la experiencia del PS en el universo sindical conserva aún múltiples interrogantes. Como se ha dicho, examinar su vínculo con el movimiento gremial ilumina al mismo tiempo una parte importante de la historia del socialismo, y de la izquierda en general, y de la clase obrera argentina de la primera mitad del siglo XX. El vínculo entre el partido y los sindicatos fue eje de debates entre los socialistas a nivel internacional desde fines del siglo XIX. El PS argentino, casi desde su creación planteaba tres áreas de acción de cara a los trabajadores. El gremialismo, el cooperativismo y la acción política (entendida mayormente ligada al plano electoral y parlamentario), se erigían como campos relacionados pero con sus especificidades (Oddone 1949, 287). Desde sus orígenes, aunque con fuertes debates, la voluntad oficial, en gran medida impulsada por su máxima figura y referente Juan B. Justo, fue la de escindir el plano político del gremial (Poy 2014; Belkin 2018; Martínez Mazzola 2011). Esta autonomía, materializada en la 'Declaración de Avellaneda' del XIV Congreso Ordinario en 1918, era una expresión de una concepción más amplia sobre la necesidad de construir una opción partidaria reformista, que buscara la integración al sistema social y político y que subordinara la conflictividad entre capital y trabajo a elementos más globales, entre otras 
características. Pero esta desarticulación de esferas, que si se quiere ir más allá fue incluso una disociación con algunos aspectos centrales de la lucha y la organización obrera, estuvo sujeta a fuertes tensiones internas y cuestionamientos (Camarero 2015; Ceruso 2019). Esta política evidenció modulaciones y fue cuestionada tanto como defendida durante los años treinta en diferentes momentos siempre teniendo como animadores centrales a la dirección partidaria y al sector compuesto principalmente por cuadros gremiales y liderados por Francisco Pérez Leirós, figura del sindicato de municipales de la Capital Federal y la más relevante del socialismo en este campo, como eje de los cuestionamientos a la política oficial y tradicional del PS.

\section{La agencia laboral y el sindicalismo en los inicios de la década infame}

Tras los sucesos del golpe de Estado de septiembre de 1930, el abogado Eduardo Maglione ocupó el máximo cargo del DNT hasta mayo de 1931. Como es sabido, su breve estadía al mando del organismo contrastó con la vitalidad que buscó imprimirle no solo en la reorganización interna sino en su funcionalidad en la dinámica del mundo del trabajo.

Asimismo, la recientemente fundada CGT realizó su debut público y empezó a definir su postura frente a la dictadura. Un tribunal militar había dictado sentencia de condena de muerte para tres choferes del sindicato de la Federación Obrera Regional Argentina (FORA) que habían tenido un enfrentamiento armado con la policía. Ante la presión, su manifestación fue un tenue pedido de conmutación de pena y un voto de confianza al gobierno (Marotta 1970, 309). Aunque adjudicada al secretario general Luis Cerutti por el mismo Sebastián Marotta, la declaración mostraba los esmeros de colaboración de la central y esto la expuso a severas críticas. En sintonía con ello, la CGT mantuvo conversaciones con el gobierno, en particular con las estructuras del DNT bajo la gestión de Maglione, que le permitieron ejercitar a la conducción sindicalista las cualidades negociadoras practicadas con especial énfasis durante los gobiernos radicales. En este ejercicio, los socialistas dentro de la central obrera no fueron a la zaga pues como observaremos valoraron positivamente la política laboral de la 
dictadura durante los primeros meses. Esto no significa bajo ningún aspecto que militantes de base y cuadros medios de ambas corrientes no sufrieran cotidianamente la represión, tortura, encarcelamiento y deportación que, como complemento, impulsaba el gobierno.

Como se ha estudiado, un cuerpo de ideas ligadas al antiliberalismo y con influencias corporativistas, nacionalistas y católicas pretendieron moldear el funcionamiento inicial de la agencia laboral y la definición del cuerpo de funcionarios (González Bollo 2008; Rubinzal 2013). El mismo Maglione planteaba los objetivos en el discurso al asumir el cargo y los lineamientos para fortalecer los mecanismos de conciliación:

en cuanto a la forma de conciliación de los conflictos entre el Capital y el Trabajo, se debe propender tanto por los patrones o empleadores como por los trabajadores y obreros, a la asociación y agremiación por industrias y comercios, en la conveniencia de aunar y uniformar voluntades para resolver conflictos generales, en la imposibilidad absoluta de dedicar atención particular a cada uno de los conflictos separados de cada industria o comercio. Esa asociación y agremiación facilitará la constitución de tribunales o comisiones mixtas o paritarias que servirían, primero, de conciliación de los intereses encontrados, y luego de arbitraje en el caso extremo de no arribar las partes por mutuos acuerdos y concesiones a un punto coincidente de solución. De esas mismas comisiones saldrán los contratos colectivos de trabajo, que aunque no obligatorios por la ley, las partes pueden, sin embargo, celebrar por mutuo acuerdo, estableciendo las formas y garantías para respetarlos. ${ }^{8}$

Los socialistas se expresaban a favor de la instalación de estas comisiones mixtas: "el PS reclama la constitución de comisiones mixtas de patrones y obreros para la vigilancia de la legislación del trabajo". ${ }^{9}$ De igual

\footnotetext{
${ }^{8}$ Ministerio del Interior, Departamento Nacional del Trabajo, División de Estadística, Crónica Mensual, Buenos Aires, XIII, 151, septiembre de 1930, p. 3311. Una visión de los objetivos que se trazaba en Eduardo Maglione, "Mi experiencia en el Departamento Nacional del Trabajo", conferencia pronunciada en la Asociación Florencio Sánchez, en Revista de Derecho Social, núm. 2, 1931, pp. 143 y ss.

9 "El cumplimiento de las leyes obreras", La Vanguardia, XXXVII, 8440, 10/11/1930, p. 5 .
} 
modo, La Vanguardia reprodujo de forma completa y elogiosa la conferencia que brindó el presidente del DNT entre los días 29 de julio y el 1 de agosto de 1931 una vez abandonado el cargo en donde repasaba su proceder y hacía gala de su pretendida intención de dotar de supuesta imparcialidad a la institución:

se ha demostrado así que cuando hay una voluntad firme y honrada se pueden hacer cumplir y se hacen cumplir las leyes del trabajo. Contra esta firme y honesta decisión no pueden absolutamente nada ni la resistencia obcecada de ni la misma complicidad interesada de las clases beneficiarias y ni siquiera la incomprensión de las clases gubernamentales. ${ }^{10}$

Este ordenamiento del mundo sindical se hizo distinguiendo nítidamente entre aquellos mecanismos autorizados como el derecho de reunión o asociación, de aquellos considerados ilegítimos y por tanto ilegales como el boicot y el sabotaje. En este sentido, la actitud del PS comenzó a definirse calificando de "interesante" la declaración del DNT en donde caracterizaba a esa acción directa como métodos de protesta "extralegales":

el gobierno les respeta los derechos de reunión, de asociación y de huelga, siempre que estas actividades se encuadren, como se ha dicho, dentro del margen estricto de la ley: pero al mismo tiempo reafirma su voluntad de no aceptar imposiciones ni procedimientos extralegales, como el sabotaje o el boicot, que reprimirá por todos los medios que tiene a su alcance. ${ }^{11}$

La comunicación del "gobierno provisorio" se concebía como respuesta al llamado a la huelga general de la FORA y que había tenido relativo éxito entre los portuarios y en el transporte de camiones, colectivos y taxis (Iñigo Carrera 2016, 108). Aunque cuando procuraba intervenir en conflictos donde los métodos no eran los propios de la acción directa, el DNT se

\footnotetext{
10 “Acerca de sus impresiones sobre el Departamento Nacional del Trabajo, habló el doctor Maglione”, La Vanguardia, XXXVII, 8694, 30/7/1931, p. 5.

11 "Cómo interpretará y aplicará el gobierno provisorio la legislación obrera", La Vanguardia, XXXVII, 8408, 9/10/1930, p. 5.
} 
mostraba ineficiente frente a la negativa patronal de negociar como rápidamente en octubre de 1930 pusieron de manifiesto los conflictos de la fábrica textil Narciso Muñoz y con los telefónicos. A pesar de ello, el PS destacaba la labor cumplida por el organismo en la fiscalización y cumplimiento de la jornada de 6 horas en el sector gráfico. ${ }^{12}$ Asimismo, denunciaba el accionar policial que contraponía al proceder del DNT, quien sí había comprendido el rol educativo y civilizatorio que cumplía el sindicalismo en la clase trabajadora (Tortti, 1989). ${ }^{13}$ En este último sentido destacaban lo ocurrido en una de las grandes fábricas del sector, la tejeduría de algodón y fabricante de medias Salzmann (Medias París) ubicada en la calle San Antonio 741 del barrio porteño de Barracas. Como señalamos, allí, como en un gran porcentaje de las empresas textiles de la zona sur de la ciudad, los socialistas tenían un peso importante y lograron dotar de organización a la fábrica. El conflicto en esta casa comenzó a los pocos días del golpe de Estado cuando la patronal decidió una rebaja de los ya magros jornales obreros. En respuesta, se declaró la huelga y la negociación frente a los empresarios la encabezó la comisión interna del personal. ${ }^{14}$ Finalmente, los trabajadores lograron evitar la rebaja de salarios en una discusión en la que intervino activamente el DNT. ${ }^{15}$ Más allá de lo obtenido, a los pocos días, el sindicato denunciaba el incumplimiento de lo firmado entre las partes y la institución estatal dictaminó una inspección permanente para corroborarlo. ${ }^{16}$

Con la mencionada intención, este sector del cuerpo estatal llevó a cabo el Primer Congreso Nacional del Trabajo entre el 21 y el 27 de marzo de 1931 en donde se buscó posicionar al DNT en un plano nacional pues su mayor injerencia se encontraba en la Capital Federal y en la provincia de Buenos Aires, unificar criterios de legislación laboral, buscar la efectivización de los derechos firmados pero no cumplidos, aislar las

\footnotetext{
12 "Es eficaz la labor del Departamento nacional del trabajo en la aplicación de la jornada de seis horas en los talleres gráficos", La Vanguardia, XXXVII, 8487, 27/12/1930, p. 5.

13 “Basta de equívocos”, La Vanguardia, XXXVII, 8440, 10/11/1930, p. 1.

14 “Obreros textiles”, La Vanguardia, XXXVII, 8398, 29/9/1930, p. 3.

${ }^{15}$ Ministerio del Interior, Departamento Nacional del Trabajo, División de Estadística, Crónica Mensual, Buenos Aires, XIII, 151, septiembre de 1930, p. 3338.

16 Ídem, pp. 3345-3348.
} 
tendencias que se oponían a los criterios de conciliación entre capital y trabajo planteados por este grupo y presentar la problemática de los tribunales laborales y de accidentes de trabajo, entre otras temáticas (Rubinzal 2013, 230-231). En particular, no quedaban dudas del primordial objetivo del Congreso, así lo expresaba el ministro del interior, Matías Sánchez Sorondo, principal impulsor de Maglione, en el acto de inauguración del Congreso. Alejado de cualquier pretensión de imparcialidad o equidistancia, como en numerosas ocasiones se ha pretendido teñir al desempeño del DNT, advertía:

se ha tratado y se ha conseguido, desgraciadamente, sobre el plano de la "lucha de clases", armar en batalla una parte de la sociedad contra la otra. Se ha disciplinado así a una fracción importante de la masa obrera, infundiéndole como el alma de la propaganda el odio al capital, o mejor dicho, al capitalista, como si fueran separables en el concepto económico integral; como si el trabajo pudiera existir sin el capital, o este sin aquél (...). ${ }^{17}$

Más allá de las expectativas primigenias, Maglione reflexionaba acerca del Congreso y ubicaba su mayor influencia en haber instalado una serie de problemáticas obreras en la opinión pública, y así establecer y delimitar las metas alcanzadas. ${ }^{18}$ Paradojalmente, una visión más optimista de su gestión al frente del DNT podía encontrarse en el PS que en el marco de la realización de su XXVII Congreso Nacional del año 1932 expresaba:

la comisión preparó un plan a desarrollar, por medio de conferencias, para agitar entre los trabajadores, el cumplimiento de las leyes obreras. La ocasión fue oportuna. El ciudadano que en ese momento se encontraba frente al Departamento Nacional del Trabajo, animado con un sano propósito, se inició en su puesto aplicando rígidamente las leyes obreras.

17 "El discurso del Dr. Sánchez Sorondo", La Fronda, XII, 4267, 23/03/1931, p. 1. Citado en López Cantera 2019, 138.

${ }^{18}$ Eduardo Maglione, "Mi experiencia en el Departamento Nacional del Trabajo", conferencia pronunciada en la Asociación Florencio Sánchez, en Revista de Derecho Social, núm. 2, 1931, p. 152. 
La clase patronal de inmediato empezó a realizar con elementos mercenarios, una campaña de desprestigio, ya invocando inconstitucionalidad de algunas leyes, saboteando la labor del Departamento o haciéndole el vacío por medio de la prensa burguesa y trabajos subterráneos para desprestigiar no solo a las leyes sino también al funcionario honesto que las quería hacer cumplir. ${ }^{19}$

La renuncia de Maglione fue conceptualizada por el PS nuevamente con el prisma evolucionista y civilizatorio tan propio de su cuerpo de ideas: "el estallido de una crisis entre el espíritu atrasado y bárbaro, para el que la experiencia nada edifica, y el espíritu comprensivo que siente la imperiosa necesidad de fomentar las organizaciones obreras, verdaderas instituciones de bien social". ${ }^{20}$ Tras el interregno de Maglione, el cargo de presidente del DNT fue ocupado por Eduardo J. Bullrich y a partir de 1934 por Roberto Tieghi. En los diversos Boletines del DNT puede observarse el incremento en la injerencia en la mediación en los conflictos. ${ }^{21}$ Esta dinámica también puede registrarse desde la perspectiva de los trabajadores como por ejemplo el renovado conflicto en la empresa textil Narciso Muñoz en donde el DNT medió entre patrones y obreros ante la huelga (Horowitz 2004). ${ }^{22}$ Los planteos eran acompañados por la Unión Industrial Argentina (UIA) con la firma de acuerdos entre su sección textil y el sindicato socialista para ejercer un supuesto cumplimiento de las condiciones firmadas. ${ }^{23}$ Esta intervención gradual por supuesto no aseguraba la concreción de lo firmado y así lo reconocía la propia UIA cuando durante el año 1932 frente a la propuesta de la Comisión de Legislación del Trabajo de la Cámara de Diputados de

${ }^{19}$ XXI Congreso Ordinario (XXVII Congreso Nacional), Informes, Talleres Gráficos La Vanguardia, 1932, p. 49.

${ }^{20}$ La Vanguardia, 19/5/1931. Citado en del Campo, 2005, 86.

21 Ver Ministerio del Interior, Departamento Nacional del Trabajo, División de Estadística, Boletín Mensual, Buenos Aires, noviembre de 1932 a abril de 1933 y Ministerio del Interior, Departamento Nacional del Trabajo, División de Estadística, Boletín Informativo, junio de 1933 a diciembre de 1935.

22 "Se solucionó el conflicto que los textiles mantenían en la fábrica de Narciso Muñoz", Boletín de la Confederación General del Trabajo, II, 16, 1/5/1933, p. 6.

23 "Comisión paritaria de la industria textil para las cuestiones obreras", Anales de la Unión Industrial Argentina, XLV, septiembre de 1932, p. 47. 
reducir la jornada laboral semanal a 40 horas para bajar la desocupación se negaba con el argumento que ni siquiera se cumplía la extensión vigente de 44 horas. $^{24}$

Por último, vale recordar que durante el año 1932 Sánchez Sorondo presentó su proyecto de ley para incorporar al Código Penal la represión al comunismo pero no fue tratado hasta 1936 ya que permaneció adormecido en la discusión de las comisiones parlamentarias pertinentes. Igualmente, durante estos años no cesó el pedido de las organizaciones políticas y sindicales de los trabajadores para que se rechazase este planteo oficial que legalizó y ofreció amparo a las prácticas que, muchas de ellas, se encontraban en plena vigencia de facto y constituían la realidad cotidiana de militantes gremiales y partidarios. ${ }^{25}$

\section{Los años de Justo}

En febrero de 1932 el general Justo asumió la presidencia rodeado de un elenco conservador. Resaltaban Ernesto Hueyo en Hacienda, reemplazado por Federico Pinedo en 1933, Antonio de Tomaso en Agricultura y Leopoldo Melo en Interior. Vía fraude electoral, abstención radical y alianzas provinciales, la mayoría parlamentaria aseguró los apoyos necesarios (Macor 2001; López 2017). Más aún cuando en julio de 1932 se estructuró la denominada Concordancia en el ámbito legislativo y que tuvo su correlato en la conformación del armazón electoral y de gobierno que funcionó más como una coalición que como un partido. Resaltemos que el PS logró en ese mismo año la máxima representación parlamentaria de su historia con la obtención de los 2 senadores por la Capital Federal y 43 diputados nacionales (Portantiero 2002). Esto se debió a la ausencia de la Unión Cívica Radical pero, también, no debe desconocerse el crecimiento de un partido que priorizaba ese plano en detrimento de otros espacios de lucha.

24 “La semana de 40 horas. Objeciones formuladas por la institución”, Anales de la Unión Industrial Argentina, XLV, agosto de 1932, p. 11.

${ }^{25}$ Para el derrotero de la ley propuesta por Sánchez Sorondo ver López Cantera 2019, 236-245. 
En 1929 se sancionó la ley 11.544 que establecía la regulación de la jornada de trabajo de ocho horas así como las condiciones de insalubridad laboral que habilitaban la reducción a seis horas en algunas áreas o sectores productivos específicos. Durante el año 1933, Justo procedió a una reglamentación de dicha ley con el ya mencionado Bullrich al mando del DNT. ${ }^{26}$ Era recurrente el llamado de múltiples sindicatos al cumplimiento de la misma y la FOT no fue la excepción al reclamarle al DNT la aplicación global de las leyes de jornada laboral y la efectivización de la prohibición del trabajo femenino en áreas no permitidas. ${ }^{27}$ Asimismo, no dudaba en solicitarle reformas a dicha ley al Departamento Provincial del Trabajo (DPT). ${ }^{28}$

En la misma línea, el PS saludaba el proyecto del DNT de creación de tribunales de trabajo y comisiones de conciliación y arbitraje y en concreto apoyaba la iniciativa de la FOT de conformar una comisión paritaria de obreros y patrones para discutir la aplicación de la ley 11.544 y demás cuestiones inherentes a la mejora de las condiciones laborales, ya sea por rama de actividad o en fábricas específicas. ${ }^{29}$ Siempre destacando que en muchas ocasiones se arribaba a una solución de la huelga, como el caso de la fábrica Muñoz, por "la mediación del presidente del Departamento Nacional del Trabajo". ${ }^{30}$ En el mismo sentido, el sindicato contraponía, unos años más tarde, dicho proceder con la exigencia al DPT que cumpliera su rol de control y árbitro. ${ }^{31}$ En momentos de conflicto puntual, era el propio

${ }^{26}$ Dicha ley ya había tenido un decreto reglamentario en marzo de 1930 en donde se establecían algunas áreas de la industria textil como trabajo insalubre debido principalmente a los productos allí utilizados (Norando, 2020).

27 "En la industria textil se sigue burlando la jornada legal de trabajo", La Vanguardia, XXXVIII, 8946, 1/3/1932, p. 5.

28 "Reformas a la ley 11.544 de 8 horas", El Obrero Textil, I, 6, 11/1933, p. 2. Para indagar acerca de las particularidades y tensiones del DPT respecto del DNT puede consultarse entre otros Barandiarán, 2016.

29 "Para vigilar el cumplimiento de las leyes obreras crearon una comisión mixta en la industria textil", La Vanguardia, XXXIX, 9145, 18/9/1932, p. 4; "Tribunales del trabajo y comisiones de conciliación y arbitraje", La Vanguardia, XXXVIII, 8947, 3/3/1932, p. 5.

30 "Se solucionó satisfactoriamente el conflicto en la casa Muñoz Sauca y Salzman", La Vanguardia, XXXVIII, 8959, 15/3/1932, p. 5.

31 "Enérgicamente protesta la U. Obrera Textil", El Obrero Textil, II, 8, 8/1934, p. 2. 
DNT quien podía impulsar la creación de un Consejo del Trabajo entre patrones y obreros en su afán de buscar mecanismos de mediación y conciliación. ${ }^{32}$ De todos modos, el cumplimiento de dicha ley fue irregular y años después el DNT, a pedido de la empresa Grafa, continuaba con los intentos de otorgar un marco legal preciso y reglamentar sobre trabajo insalubre en la sección de cardado en las fábricas de hilados y tejidos de algodón. ${ }^{33}$

Como ha sido estudiado en detalle, el carácter errático y mayormente nominal de la legislación por atender los aspectos reproductivos de las trabajadoras pretendió ser nuevamente abordado a mediados de la década. Esto cobraba particular relevancia en el gremio textil pues, como dijimos, su fuerza de trabajo estaba compuesta mayoritariamente por mujeres. Así, en octubre de 1934 se sancionó la ley 11.933, a propuesta del senador socialista de la Capital Federal Alfredo Palacios, referida al Seguro de Maternidad:

sus disposiciones más importantes fueron la prohibición del trabajo femenino en las industrias y comercios durante los treinta días anteriores al parto y los cuarenta y cinco que le seguían, el establecimiento de un subsidio equivalente a un porcentaje de su salario y la concesión de servicio médico u obstétrico. Cabe resaltar que el sueldo se dejaba de cobrar por el tiempo otorgado de licencia. Los fondos para solventar el gasto se constituirían a través de aportes obligatorios realizados por cada trabajadora cuya edad estuviera comprendida entre los 15 y los 45 años, un aporte igual realizado por parte de los patrones y otra por el Estado. Las cuotas se abonarían trimestralmente y su valor equivalía a una jornada de trabajo. (Ramacciotti 2004-2005)

Se ha destacado la exaltación de las características femeninas ligadas estrechamente al discurso sobre la maternidad y la apelación que hacía de ello, y a partir de ello, el Estado (Nari, 2004). Era esa misma identidad

\footnotetext{
32 "Entre la Casa Salzman y los obreros textiles firmóse una tregua", La Vanguardia, XXXIX, 9258, 10/1/1933, p. 4.

33 Boletín Informativo del Departamento Nacional del Trabajo, № 198-199, julio y agosto de 1936, p. 4630.
} 
maternal a partir de la cual de modo usual y reiterado el propio sindicato interpelaba a las trabajadoras. ${ }^{34}$ La iniciativa del Seguro de Maternidad fue saludada por el PS y se hicieron múltiples actos de apoyo al proyecto y al pedido de reglamentación, hecho que sucedió dos años más tarde, en abril de $1936 .^{35}$

En paralelo, la convivencia de los socialistas y los sindicalistas en la CGT distaba de ser cordial. Las internas se incrementaron. El primer grupo integrado por miembros de la Comisión Socialista de Información Gremial (CSIG), dependiente del PS, y sindicalistas descontentos con la conducción reclamaban una mayor representación de los sindicatos a los que pertenecían (principalmente ferroviarios pero también tranviarios, comercio y municipales) en los cargos directivos aunque no se privaron de anclar su crítica en la prescindencia política que declamaba la central. ${ }^{36} \mathrm{El}$ otro sector estaba formado mayoritariamente por los sindicalistas que controlaban la CGT. En diciembre de 1935 el clima de enfrentamiento se exacerbó cuando la Unión Ferroviaria (UF), ya bajo la secretaría general del socialista José Domenech, pretendió modificar sus delegados en la central en el marco del llamado de la dirigencia cegetista al largamente demorado Congreso Constituyente para marzo de 1936. El 12 de diciembre los eventos se precipitaron cuando los opositores ingresaron por la fuerza a la sede de la CGT y declararon depuestas a las autoridades. ${ }^{37}$

El golpe interno provocó la división y, a partir de allí, existieron dos CGT: la 'socialista', con mayor número de sindicatos y obreros afiliados y cuyo núcleo eran los gremios ferroviarios (UF y La Fraternidad) junto con

\footnotetext{
${ }^{34}$ Solo a modo de ejemplo: "La madre", El Obrero Textil, V, 24, 12/1938, p. 4.

35 "La ley de protección a la maternidad", Vida Femenina, IX, 101-102, junio y julio de 1942, pp. 4-9, "La ley de protección de la maternidad”, El Obrero Textil, V, 12, 10/1936, p. 5, "La protección a la mujer obrera", El Obrero Textil, IV, 9, 3/1935, p. 4 y "Reglamentose la ley de protección a la madre empleada u obrera", El Obrero Textil, IV, 11, 1/5/1936, p. 9.

${ }^{36}$ La importancia de la CSIG en la reyerta de la CGT había cobrado relevancia y era acusada desde distintos sectores como la causante de la discordia.

${ }^{37}$ Las dos versiones en Oddone 1949, 332-351; Marotta 1970, 411-433. Además en: "Ayer hizo crisis el conflicto latente en la central obrera", La Vanguardia, XLI, 10320, 13/12/1935, p. 7; "Cómo se premeditó y cómo se consumó el asalto a la CGT", Libertad, diario de la mañana, ("Órgano oficial del Partido Socialista Independiente”), IX, 2608, 29/12/1935, p. 1.
} 
los tranviarios, comercio y municipales; y la 'sindicalista', compuesta por un escaso número de empleados telefónicos y marítimos, principalmente. La primera central fue reconocida como CGT Independencia, mientras que la sindicalista como CGT Catamarca; en ambos casos el nombre se debió a las calles en donde se ubicaban sus oficinas. Tras la ruptura con el sector tradicional de la corriente sindicalista, la CGT parecía estar dejando atrás la prescindencia para volcarse hacia posturas de mayor participación en las cuestiones políticas de interés obrero. Ello pronto se demostró un diagnóstico incorrecto o apresurado pues el núcleo dirigente, mayormente socialistas, de la CGT rápidamente mostró su afección por separar la labor de la central obrera de la de los partidos políticos. La manifestación pública y el involucramiento frente a los hechos de la realidad nacional e internacional dividían aguas. Pronto, en la CGT, quedaron representados dos bandos (Camarero 2015; Ceruso 2019). El primero, compuesto por socialistas, algunos sindicalistas todavía existentes y los líderes sindicales de la Unión Ferroviaria, menos tendiente a involucrarse en cuestiones políticas y partidarias. Allí revistaban José Domenech y Camilo Almarza, entre los dirigentes más importantes. El segundo, formado por los comunistas y los socialistas más ligados a la estructura del PS, más propensos a dirimir cuestiones a través de la política y los partidos, entre quienes estaban los comunistas Guido Fioravanti y Pedro Chiarante y el socialista Pérez Leirós (Matsushita 1986, 166 y ss). Estas diferencias entre los grupos se fueron evidenciando frente a numerosos acontecimientos, por ejemplo en los discursos en torno al acto unitario, tanto como inusual, del

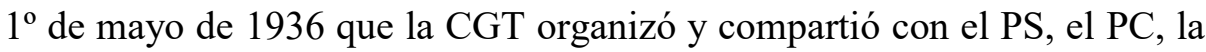
Unión Cívica Radical, los demócratas progresistas, estudiantes y gremios autónomos, entre otros (del Campo 2005, 142).

Con la toma de las riendas de los socialistas en la CGT Independencia, los comunistas vieron la posibilidad de sumarse a la central obrera, en línea con la orientación de 'frente popular'. La III ${ }^{\mathrm{O}}$ Conferencia Nacional del Partido Comunista, en octubre de 1935, siguiendo las resoluciones del $\mathrm{VII}^{\circ}$ Congreso de la Comintern, marcó el inicio de la política de frente popular. ${ }^{38}$

\footnotetext{
${ }^{38}$ La política de frente popular habilitó acuerdos con las fuerzas obreras "reformistas", e incluso con los sectores "progresistas" de la burguesía, bajo preceptos antiimperialistas y antifascistas.
} 
De este modo, la tradicional presencia sindical socialista y la creciente inserción comunista en el ámbito industrial, sentaron las bases de una potente central obrera. Esta situación, junto al cambio en la dirección de la CGT a fines de 1935, permitió que los comunistas disolvieran su sindicato y se sumaran a la UOT. Así, se conformó el sindicato único textil con sede en la calle Cochabamba 1760.

Entonces, el año 1936 mostró el avance de la UOT, ahora ya, cambio estratégico mediante, con los comunistas incorporados al sindicato, que aún era dirigido por cuadros del socialismo. En este marco, y en el de una CGT revitalizada, la UOT emprendió la búsqueda de una mayor organización y para ello entabló demandas de mejoras y reconocimiento frente al Estado y las entidades empresariales textiles. La firma del convenio colectivo en el sector lanero entre la UOT y la Confederación Argentina de Industrias Textiles, con la participación del DNT, desde septiembre de 1934 bajo las órdenes de Tieghi, marcó un punto de inflexión en la búsqueda del sindicato por aumentar su injerencia y representación entre los obreros. ${ }^{39}$ La UOT intentó ampliar este tipo de convenios al resto de las ramas del sector como la algodonera y la seda, entre otras. Esta coyuntura permitió al sindicato ganar posiciones obteniendo un paulatino incremento de las afiliaciones y de las cotizaciones. El contexto posibilitó un aumento de las huelgas que protagonizaron los obreros textiles entre las que se destacó la que impulsaron las trabajadoras de Gratry en el que una serie de sucesos resultan de nuestro interés. ${ }^{40}$

Establecimientos Americanos Gratry estaba ubicada en Av. Coronel Roca 1516, en el barrio porteño de Nueva Pompeya. Dedicada a la tejeduría de algodón y con más de 800 obreros era una de las textiles más importantes de la época. Además de ampliar su predio para aumentar la producción, la empresa construyó allí mismo un edificio en el que vivían gran parte de los

\footnotetext{
${ }^{39}$ Esta entidad patronal textil fue creada en 1932 y en ella se encontraban representadas las principales empresas del sector. "Se ha constituido una Confederación de Industrias Textiles", La Gaceta Algodonera, publicación defensora de plantadores e industriales del algodón, IX, 103, 31/8/1932, p. 15.

${ }^{40}$ Durante 1936 se registraron 109 huelgas y los trabajadores textiles fueron el segundo grupo de mayor actividad detrás de los obreros de la construcción. Ministerio del Interior, Departamento Nacional del Trabajo, División de Estadística, Investigaciones Sociales. Síntesis de los resultados obtenidos en 1936, Buenos Aires, 1936, p. 11.
} 
obreros y obreras con sus familias. ${ }^{41}$ El conflicto en la empresa Gratry se desarrolló durante cuatro meses y obtuvo la solidaridad de gran parte de los comerciantes y vecinos de los barrios aledaños. La huelga efectivamente comenzó el 20 de abril producto del despido de unas obreras por solicitar aumento de salarios. El reclamo, entonces, incluyó la suba de salarios y mejoras en las condiciones de trabajo junto a la reincorporación de las despedidas. ${ }^{42}$

El desarrollo del conflicto tuvo características violentas. La empresa en un primer momento contrató a rompehuelgas pero las trabajadoras realizaron un cerco que impidió el acceso a la fábrica. La represión policial en la calle y en las viviendas de la zona fue la respuesta patronal y estatal. La solidaridad de los comerciantes de Nueva Pompeya, Parque Patricios y Villa Soldati se materializó en un paro que se realizó el 31 de julio y en la continua ayuda a los huelguistas y sus familiares.

Las negociaciones se desarrollaron con la intervención de la dirigencia sindical, los representes de la empresa y el DNT, a pedido de la UOT. ${ }^{43} \mathrm{La}$ empresa Gratry desconoció la representación del sindicato y ante la consulta, el DNT le respondió que era con la UOT con quien debía negociar. Cuando finalmente el sindicato y la fábrica se dispusieron a las conversaciones, el DNT invitó a los empresarios a ser más "conciliadores" y abandonar la intransigencia que suponía no reconocer nada del pliego de condiciones. Aunque las tratativas, como era usual, continuaron con el jefe de policía. ${ }^{44}$ La huelga se extendió hasta fines del mes de agosto, cuando la presencia policial en el barrio, la dificultad para convocar a asambleas, el desgaste propio del conflicto, entre otros motivos, hicieron que el comité de huelga levantara la medida.

\footnotetext{
${ }^{41}$ Grupo de Investigación Histórica de Nueva Pompeya, La Huelga de los conventillos de Pompeya: lucha obrera en la textil Gratry en 1936, Buenos Aires, edición propia, 2009.

42 "A los compañeros y compañeras de la Gratry, a todos los que han cooperado con nosotros", Informe y balance del comité de huelga de la casa Gratry, septiembre de 1936, p. 1.

${ }^{43}$ Informe y balance del comité de huelga de la casa Gratry, Buenos Aires, septiembre de 1936.

44 "Huelga de la casa 'Gratry", El Obrero Textil, V, 12, 10/1936, pp. 2, 3, 4.
} 
Durante todo el año 1937 la UOT intentó avanzar en la firma de convenios colectivos por sectores productivos. Hacia fines de aquel año tras una serie de conflictos parciales obtuvo un acuerdo con la Confederación Argentina de Industrias Textiles que representaba a los empresarios de la lana y en el cual intervino activamente el DNT bajo las órdenes de Tieghi (Di Tella 2003, 291). El acuerdo no sólo otorgaba amplias facultades regulatorias a la institución laboral sino que también conformaba las comisiones mixtas de patrones y obreros como ámbitos de discusión. ${ }^{45} \mathrm{En}$ la provincia de Buenos Aires, las negociaciones se llevaron adelante con el DPT y el acuerdo llegó tras una serie de conflictos en las fábricas productoras de lana. ${ }^{46}$ Ese mismo año el DNT decretó la conformación del Consejo del Trabajo de la industria textil para analizar las condiciones generales del sector. ${ }^{47}$

Desde principios de 1938 la UOT inició los preparativos para reformar sus estatutos, que finalmente se aprobaron en febrero de 1939, como un intento de mayor institucionalización. Incluso no resultaba extraño que la UOT advirtiera como prioritario la obtención de la personería jurídica y el reconocimiento estatal como, señalaba, la tenían ferroviarios y municipales, entre otros, porque de ese modo estarían más amparados en las negociaciones. ${ }^{48}$ De hecho, el sindicato elevó un memorial al ministro del interior para solicitar la personería y ante el Congreso de la Nación por el cumplimiento de las vacaciones pagas, vía el reconocimiento y extensión de la ley 11.729 sancionada durante 1934 y que otorgaba una serie de derechos (licencias, indemnización, entre otras) a los empleados de comercio. Aunque de difícil cumplimiento, en muchas empresas su implementación generó que en los años sucesivos parte de la discusión en las organizaciones

45 "Se llegó a un acuerdo previo entre patrones y obreros de la industria lanera",
Argentina Fabril, ("Publicación semanal del órgano de publicidad de la Asociación
Unión Industrial Argentina"), L, febrero de 1937,818, p. 16 .
46 "Entran en su faz constructiva las discusiones relacionadas con el pliego de
condiciones", El Obrero Textil, V, $15,2 / 1937$, p. 1 .
47 "Se ha constituido el Consejo del Trabajo en la industria textil", El Obrero Textil, V,
14, 1/1937, p. 1 ; Boletín Informativo del Departamento Nacional del Trabajo, N $204-$
205 , enero y febrero de 1937 , p. 4848 ; "Entran en su faz constructiva las discusiones
relacionadas con el pliego de condiciones", El Obrero Textil, V, $15,2 / 1937$, p. 1
48 "A reforzar la UOT es el deber de los textiles", El Obrero Textil, V, $21,5 / 1938$, p. 5. 
sindicales pasara por su aplicación a los obreros de la industria. ${ }^{49}$ Durante 1938, fueron recurrentes los pedidos de la UOT al DNT para que controlara el cumplimiento de los convenios firmados. ${ }^{50}$ Para ello, el DNT propició la creación de una comisión especial de interpretación de lo firmado por las asociaciones patronales y obreras y un órgano permanente de relaciones entre la Confederación Argentina de Industrias Textiles y la UOT. ${ }^{51}$

El predominio socialista en el sindicato se interrumpió en 1939 con la llegada del comunista Jorge Michellón a la secretaría general de la UOT, reflejo del incesante crecimiento del PC en el mundo sindical industrial, en general, y en el gremio textil, en particular. Este hecho, entre otros que conformaban la coyuntura nacional e internacional, produjo un paulatino deterioro de las relaciones. ${ }^{52}$ Los comunistas denunciaron las maniobras socialistas calificándolas de 'divisionistas' y argumentando que se debían a la obtención de la conducción. El relato de la publicación anarquista que agrupaba a los gremios autónomos orientados por la Federación Anarco Comunista Argentina apoyaba la versión socialista acerca de las anomalías alrededor de la asamblea general. ${ }^{53}$ La ruptura definitiva ocurrió a mediados de 1941 cuando los socialistas crearon otro sindicato también denominado UOT. Así, de allí en más, quedaron conformadas dos entidades con el

49 "La UOT ha impuesto al poder ejecutivo de la grave situación en la industria", El Obrero Textil, V, 23, 7/1938, pp. 1 y 3.

50 "Una delegación de la UOT se entrevistó con el presidente del Departamento N. del Trabajo", El Obrero Textil, V, 22, 6/1937, p. 1.

${ }^{51}$ Ministerio del Interior, Departamento Nacional del Trabajo, Boletín Informativo, $\mathrm{N}^{\mathrm{o}}$ 208-209, mayo y junio de 1937, p. 4982.

52 Ese mismo año, en 1939, las relaciones entre socialistas y comunistas se deterioraron aceleradamente producto del inicio de la Segunda Guerra Mundial. Principalmente, cuando los reclamos comunistas de condena frente al nazismo y el fascismo y a favor de la democracia y las libertades se interrumpieron a mediados de agosto de 1939 con la firma del pacto germano-soviético de no agresión firmado por el ministro de Asuntos Exteriores del III Reich, Joachim von Ribbentrop, y el comisario soviético de Asuntos Exteriores, Viacheslav Molótov, el 23 de agosto. Ello implicó un repentino neutralismo por parte del PC y de sus principales figuras políticas y sindicales que motivó críticas desde diversos sectores y profundizó las divisiones ya existentes dentro de la CGT, y fuera de ella (Piro Mittelman, 2019).

53 "Un obrero textil habla para 'Solidaridad Obrera", Solidaridad Obrera, una voz obrera y campesina de orientación y de lucha, I, 4, junio de 1941, p. 3. 
mismo nombre, la UOT conducida por los comunistas, la mayoritaria, con sede en la avenida Entre Ríos y, por el otro, el sindicato textil, de muy limitada incidencia, dominado por los socialistas y con sede en la calle Independencia (Ceruso 2015). ${ }^{54}$

\section{Reflexiones finales}

Como sostuvimos al inicio, el desafío de este trabajo consistió en encarar la experiencia conjunta de tres actores sociales: una agencia estatal, el Departamento Nacional del Trabajo; un sindicato industrial, la Unión Obrera Textil; y un partido político, el Partido Socialista. La originalidad de posar la mirada sobre la mecánica relacional de los tres sujetos posibilitó arribar a una serie de inferencias.

Respecto del DNT, más que la voluntad de establecer elementos de disparidad (Torre 1990) o lazos de continuidad (Soprano 2000) con la futura Secretaría de Trabajo y Previsión y su desenvolvimiento e incidencia, se promovió una mirada que priorizó el análisis entre la agencia estatal, el sindicato textil y el PS en su propia dinámica temporal. En primer término, la historiografía ya había destacado el avance y la transformación sufrida por el DNT que habilitó su vigorización durante los años treinta. Asimismo, en ocasiones, ese proceso ha sido abordado de modo unidireccional solo analizado desde la voluntad estatal y sin cotejar la dinámica social con otros interlocutores (Soprano 2000; Lobato y Suriano 2013). Trasvasar dicho institucionalismo coadyuvó para evidenciar la existencia de un doble proceso de institucionalización: el de la agencia estatal y el de la organización sindical. Junto al ya estudiado reforzamiento del DNT como 'canal de mediación' entre capital y trabajo, pudimos dar cuenta de los esfuerzos de la UOT en concretar diversos planos e instancias para corporizarse como actor formal. El sindicato textil no solo acompañó, sino que más bien demandó dicho rol para el DNT. Y en ello los preceptos gremiales socialistas tuvieron injerencia.

\footnotetext{
${ }^{54}$ Ministerio del Interior, Departamento Nacional del Trabajo, División de Estadística, Crónica Mensual, época VIII, XXIV, 241/242/243, julio, agosto y septiembre de 1942, p. 197.
} 
Como hemos señalado, el PS construyó un cuerpo de ideas específico en torno al gremialismo: la independencia de esferas entre lo político y lo gremial, su concepción evolutiva, la valoración de la acción política como superadora de la incierta práctica huelguística $\mathrm{y}$, en definitiva, la exterioridad que proponía el Partido en relación al movimiento sindical: “el Partido Socialista no debe inmiscuirse en la organización gremial. Colectivamente sólo puede y debe servirla desde afuera en cuanto las leyes, el gobierno y la administración pública atañen a la organización gremial”, en palabras del propio Juan B. Justo ([1917] 1947, 301). Pero, además:

de manera más general, se pensaba la relación Partido/movimiento obrero en términos de educación, entendida en sentido amplio, lo que incluía la importancia de un trabajo constructivo, vía la legislación. La interacción se daba, en definitiva, por fuera del movimiento obrero, ante todo en el ámbito parlamentario, donde los legisladores socialistas actuaban como poleas de transmisión de los reclamos gremiales, que pasaban a su vez por ese tamiz reformista. (Herrera 2016, 42)

La concepción evolutiva, los reparos a la autodeterminación obrera y el rechazo a la violencia argumentaban una postura contraria a las huelgas, todas pilastras de una concepción más amplia sobre la necesidad de construir una opción partidaria reformista (Camarero 2011, 60; Ceruso 2019). Pero a esas convicciones de más larga data, se le sumaron los cambios programáticos del PS durante la década del treinta que lo condujeron, a grandes rasgos, hacia un "viraje hacia la intervención estatal y las políticas públicas" (Portantiero 2005, 319; Tortti 2009). Ello también influyó a la hora que la voluntad intervencionista estatal encontrara un sólido interlocutor en el gremialismo. Además, quizá, fue esa misma esperanza intervencionista la que inhibió al PS de ponderar la política del DNT, y de Maglione en esos primeros años más nítidamente, como el complemento consensual de los fundamentos coercitivos del periodo. Se limitó a destacar, muy enfáticamente, los elementos positivos de aquellas intervenciones más que a caracterizarlas como la expresión de un tándem. Quizá allí se encuentren algunos de los principios fundantes de dicho apoyo más que en "el Partido parece haber querido justificar su oposición al 
radicalismo señalando algo positivo en la política laboral del nuevo presidente del Departamento Nacional del Trabajo" (Matsushita 1986, 85).

En definitiva, se procuró indagar en los estrechos lazos que vincularon al Estado, el movimiento sindical industrial y a la izquierda en este período y que permitieron coadyuvar a gestar una profusa experiencia. Nuestra exploración buscó captar esta heterogénea dinámica y verificar, una vez más, que la historia debe ser abordada de modo complejo, sin simplificaciones que acoten el horizonte reflexivo. En definitiva, y con los reparos que ameritan las diferentes limitaciones oportunamente marcadas, aprehender esta complexión es lo que creemos que permitió en estas páginas profundizar el conocimiento sobre la dinámica política y social del periodo.

\section{Referencias}

Barandiarán, Luciano. 2016. "Los organismos laborales provinciales: diferencias y semejanzas a partir del caso bonaerense en la etapa previa al peronismo". Cuadernos de Historia. Serie economía y sociedad 16: 65-101.

Belkin, Alejandro. 2018. Sindicalismo revolucionario y movimiento obrero en la Argentina: de la gestación en el Partido Socialista a la conquista de la FORA (1900- 1915. Buenos Aires: Imago Mundi/Ediciones CEHTI.

Bertolo, Maricel. 2011. "Los primeros pasos de la negociación colectiva en la Argentina”. Cuadernos del Ciesal 10: 71-95.

Camarero, Hernán. 2007. A la conquista de la clase obrera. Los comunistas y el mundo del trabajo en la Argentina, 1920-1935. Buenos Aires: Siglo Veintiuno Editora Iberoamericana.

—. 2011. "Del auge al declive: las corrientes de izquierda y los trabajadores antes del peronismo. Elementos para una interpretación teórica e historiográfica global". Iberoamérica Global 2: 49-79. Permalink: https://www.iberoamericaglobal.org/\#!vol4-num2nov2011/c1zu3.

. 2015. "La CGT en disputa. Prescindencia apolítica de la dirección sindicalista y frentepopulismo comunista, 1935-1939”. Cuadernos del Ciesal 14: 35-58. 
Ceruso, Diego. 2014. "El comunismo argentino y sus divisiones en los años veinte. Un análisis de la disputa en el movimiento sindical entre el 'penelonismo' y el Partido Comunista". Izquierdas, una mirada histórica desde América Latina 18: 37-56.

2015. La izquierda en la fábrica. La militancia obrera industrial en el lugar de trabajo, 1916-1943. Colección Archivos. Buenos Aires: Imago Mundi.

—. 2019. "El vínculo entre las izquierdas y el movimiento obrero. Un análisis de la experiencia del Partido Socialista argentino en los últimos años de la década de 1930". Nuevos Mundos Mundos Nuevos. París, L'Ecole des Hautes Etudes en Sciences Sociales.

Comité editor. 2012. "Presentación". Archivos de historia del movimiento obrero y la izquierda 1: 5-10.

del Campo, H. 2005. Sindicalismo y peronismo. Los comienzos de un vínculo perdurable (1983). Buenos Aires, Siglo Veintiuno Editores.

Devoto, Fernando. 2002. Nacionalismo, fascismo y tradicionalismo en la Argentina moderna. Una historia. Buenos Aires: Sudamericana.

Di Tella, Torcuato S. 2003. Perón y los sindicatos. El inicio de una relación conflictiva. Buenos Aires, Ariel.

Dorfman, Adolfo. 1942. Evolución industrial argentina. Buenos Aires: Losada.

González Bollo, Hernán. 2008. "José Francisco Figuerola: de funcionario del estado interventor conservador a experto de la coalición peronista (1930-44). Primer Congreso de Estudios sobre el Peronismo. Universidad de Mar del Plata.

Gramsci, Antonio. 1981. Cuadernos de la cárcel (1975), Tomo 3, Cuaderno 8. México: Ediciones Era.

Herrera, Carlos. 2016. ¿Adiós Al Proletariado? El Partido Socialista bajo el peronismo (1945-1955). Buenos Aires: Imago Mundi.

Horowitz, Joel. 2004. Los sindicatos, el Estado y el surgimiento de Perón, 1930-1946. Buenos Aires: Eduntref.

Iñigo Carrera, Nicolás. 2016. La otra estrategia. La voluntad revolucionaria (1930-1935). Buenos Aires: PIMSA-Imago Mundi.

Justo, Juan B. (1917) 1947. La organización obrera y el PS. En Obras de Juan B. Justo. Tomo 6. La realización del socialismo. Buenos Aires: La Vanguardia. 
Korol, Juan Carlos y Claudio Belini. 2012. Historia económica de la Argentina en el siglo $X X$. Buenos Aires: Siglo Veintiuno Editores.

Lobato, Mirta y Juan Suriano. 2013. “Conclusión. Del Departamento Nacional del Trabajo al Ministerio de Trabajo: conformación y metamorfosis de las instituciones laborales". Lobato, Mirta y Juan Suriano. La sociedad del trabajo. Las instituciones laborales en la Argentina (1900-1955). Buenos Aires: Edhasa.

López, Ignacio. 2017. "En la «hora de la espada» y bajo el signo de la reconstrucción. Liderazgo presidencial en tiempos de Agustín Justo, Roberto Ortiz y Ramón Castillo (1932-1943)". POSTData 22: 437-473. http://www.revistapostdata.com.ar/v2/wpcontent/uploads/2017/12/L\% C3\%B3pez.pdf

López Cantera, Mercedes Fernanda. 2019. “Orígenes y consolidación del anticomunismo en Argentina (1917-1943)". Tesis de doctorado. Facultad de Filosofía y Letras. Universidad de Buenos Aires.

Macor, Darío. 2001. "Partidos, coaliciones y sistema de poder". En Crisis económica, avance del Estado e incertidumbre política (1930-1943), Tomo VII de la Nueva Historia Argentina, editado por Alejandro Cattaruzza, págs. 49-95. Buenos Aires: Sudamericana.

Marotta, Sebastián. 1970. El movimiento sindical argentino. Su génesis y desarrollo. Tomo III. Período 1920-1935. Buenos Aires: Lacio.

Martínez Mazzola, Ricardo. 2018. "La neutralidad como problema y como solución. La política gremial del Partido Socialista después de la ruptura sindicalista". Identidades 1: 2-20.

Matsushita, Hiroshi. 1986. Movimiento Obrero Argentino, 1930-1945: Sus proyecciones en los orígenes del peronismo. Buenos Aires: Hyspamérica.

Nari, Marcela. 2004. Políticas de maternidad y maternalismo político. Buenos Aires, 1890-1940. Buenos Aires: Biblos.

Norando, Verónica. 2020. Rojas. Clase, género Y Militancia Comunista (1936-1946). Buenos Aires: Imago Mundi.

Oddone, Jacinto. 1949. Gremialismo proletario argentino. Buenos Aires: La Vanguardia.

Piro Mittelman, Gabriel. 2019. "El giro neutralista del Partido Comunista argentino y los efectos sobre su alianza con el Partido Socialista (1939- 
1941)". Archivos de historia del movimiento obrero y la izquierda 14: 141-161. https://doi.org/10.46688/ahmoi.n14.70.

Portantiero, Juan Carlos. 2002. "Imágenes de la crisis: el socialismo argentino en la década de 1930". Prismas. Revista de Historia Intelectual 6: $231-241$.

. 2005. "El debate en la socialdemocracia europea y el Partido Socialista en la década de 1930”. En El Partido Socialista en Argentina. Sociedad, política e ideas a través de un siglo., editado por Hernán Camarero y Carlos Herrera. Buenos Aires: Prometeo.

Potash, Roberto. 1981. El ejército y la política en la Argentina 1928-1945.

De Yrigoyen a Perón (1971). Buenos Aires: Sudamericana.

Poy, Lucas. 2014. Los orígenes de la clase obrera argentina. Huelgas, sociedades de resistencia y militancia política en Buenos Aires (18881896). Colección Archivos. Buenos Aires: Imago Mundi.

Ramacciotti, K. 2004-2005. "Las trabajadoras en la mira estatal: Propuestas de reforma de la Caja de Maternidad (1934-1955)". Trabajos y Comunicaciones 30-31. Disponible en: http://www.fuentesmemoria.fahce.unlp.edu.ar/art_revistas/pr.315/pr.31 5.pdf.

Rock, David. 2010. El radicalismo argentino, 1890-1930. Buenos Aires: Amorrortu.

Rouquié, Alain. 1985. Poder militar y sociedad política en la Argentina, tomo 1 Hasta 1943. Buenos Aires: Emecé.

Rubinzal, Mariela. 2013. "El Departamento Nacional del Trabajo y la influencia antiliberal en los años treinta". En La sociedad del trabajo. Las instituciones laborales en la Argentina (1900-1955), editado por Mirta Lobato y Juan Suriano. Buenos Aires: Edhasa.

Schvarzer, Jorge. 1996. La industria que supimos conseguir. Una historia politico-social de la industria argentina. Buenos Aires: Planeta.

Soprano, Germán. 2000. "El Departamento Nacional del Trabajo y su Proyecto de Regulación Estatal de las Relaciones Capital Trabajo en Argentina, 1907-1943”. En Argentina: trabajadores entre dos guerras, Argentina: trabajadores entre dos guerras., compilado por José Pannettieri. Buenos Aires: Eudeba. 
Soprano, Germán. 2007. "Del Estado en singular al Estado en plural. Contribución para una historia social de las agencias estatales en la Argentina”. Cuestiones de Sociología 4: 19-48.

Torre, Juan Carlos. 1990. La vieja guardia sindical y Perón. Buenos Aires: Sudamericana.

Tortti, María Cristina. 1989. "Estrategia del Partido Socialista. Reformismo político y reformismo sindical". Conflictos y Procesos de la Historia Argentina Contemporánea 34.

—. 2009. "El Partido Socialista ante la crisis de los años '30: La estrategia de la 'Revolución Constructiva"'. Revista Socialista 4.

Vogel, Lise. (1983) 2013. Marxism and the Oppression of Women. Toward a Unitary Theory. Leiden: Historical Materialism/Brill. 